\title{
Dose-Response Relationship between Radiation Dose and Loco-regional Control in Patients with Stage II-III Esophageal Cancer Treated with Definitive Chemoradiotherapy
}

\author{
Hyun Ju Kim, MD ${ }^{1}$ \\ Yang-Gun Suh, MD, PhD'2 \\ Yong Chan Lee, MD, PhD ${ }^{3}$ \\ Sang Kil Lee, MD, $P h D^{3}$ \\ Sung Kwan Shin, $\mathrm{MD}^{3}$ \\ Byung Chul Cho, MD, PhD \\ Chang Geol Lee, MD, PhD'
}

${ }^{1}$ Department of Radiation Oncology,

Yonsei University College of Medicine, Seoul, ${ }^{2}$ Department of Radiation Oncology, National Cancer Center, Goyang,

${ }^{3}$ Division of Gastroenterology,

Department of Internal Medicine and

${ }^{4}$ Division of Medical Oncology,

Department of Internal Medicine,

Yonsei University College of Medicine,

Seoul, Korea
Correspondence: Chang Geol Lee, MD, PhD

Department of Radiation Oncology,

Yonsei Cancer Center, Yonsei University College

of Medicine, 50-1 Yonsei-ro, Seodaemun-gu,

Seoul 03722, Korea

Tel: $82-2-2228-8114$

Fax: 82-2-2227-7823

E-mail: cglee1023@yuhs.ac

Received August 5, 2016

Accepted September 21, 2016

Published Online October 6, 2016

\begin{abstract}
Purpose
The correlation between radiation dose and loco-regional control (LRC) was evaluated in patients with stage II-III esophageal cancer treated with definitive concurrent chemoradiotherapy (CRT).
\end{abstract}

\begin{abstract}
Materials and Methods
Medical records of 236 stage II-III esophageal cancer patients treated with definitive CRT at Yonsei Cancer Center between 1994 and 2013 were retrospectively reviewed. Among these, 120 received a radiation dose of $<60$ Gy (standard-dose group), while 116 received $\geq 60$ Gy (high-dose group). The median doses of radiation in the standard- and high-dose groups were 50.4 and 63 Gy, respectively. Concurrent 5-fluorouracil/cisplatin chemotherapy was administered to most patients.
\end{abstract}

\section{Results}

There were no differences in patient characteristics between the two groups except for high Karnofsky performance status and lower-thoracic lesions being more prevalent in the standard-dose group. The median progression-free survival (PFS) and overall survival (OS) times were 13.2 months and 26.2 months, respectively. Patients in the high-dose group had significantly better 2 -year LRC (69.1\% vs. $50.3 \%, p=0.002)$, median PFS (16.7 months vs. 11.7 months, $p=0.029$ ), and median OS (35.1 months vs. 22.3 months, $p=0.043$ ). Additionally, LRC exhibited a dose-response relationship and the complete response rate was significantly higher in the high-dose group $(p=0.006)$. There were no significant differences in treatment-related toxicities between the groups.

\section{Conclusion}

A higher radiation dose (> 60 Gy) is associated with increased LRC, PFS, and OS in patients with stage II-III esophageal cancer treated with definitive CRT.

\section{Introduction}

Esophageal cancer ranks ninth in cancer incidences and sixth in cancer-related deaths globally [1]. More than half of esophageal cancer patients are diagnosed with locally advanced disease and approximately $20 \%$ have resectable disease at presentation [2]. Even in patients with resectable disease, prognosis is poor after surgical resection alone, with
Key words

Esophageal neoplasms, Chemoradiotherapy,

Radiation dose-response relationship 
control (LRC) with respect to combined-modality therapy using standard-dose 50.4 Gy versus 64.8 Gy of RT for patients with locally advanced esophageal cancer and found no significant advantage to administering high-dose radiation with respect to LRC and OS $[8,9]$.

Although the recommended dose of RT has remained 50.4 Gy in the definitive CRT setting based on the results of the RTOG 94-05 trial [10], the optimal radiation dose is still controversial. This study was designed to investigate the correlation between radiation dose and LRC in patients with stage II-III esophageal cancer treated with definitive CRT.

\section{Materials and Methods}

\section{Patient characteristics}

We identified all patients treated with CRT for clinical stage II-III esophageal cancer at Yonsei Cancer Center between February 1994 and May 2013. Overall, 418 patients were retrospectively reviewed, among which 182 were excluded because of the following reasons: (1) low-dose RT administered as a palliative measure $(\mathrm{n}=22),(2)$ incomplete treatment $(n=16),(3)$ esophagectomy after CRT $(n=80),(4)$ other primary cancer history $(\mathrm{n}=11)$, (5) intraluminal brachytherapy ( $\mathrm{n}=46)$, and (6) follow-up loss after CRT ( $\mathrm{n}=7$ ). Ultimately, 236 patients were included in this analysis, and their electronic medical records were retrospectively reviewed.

Pretreatment evaluation included previous medical history, physical examination, symptoms, and performance status. Laboratory studies included a complete blood cell count and routine chemistry. For staging workup, barium swallow, esophagogastroduodenoscopy (EGD), transesophageal endoscopic ultrasonography, and computed tomography (CT) of the chest and abdomino-pelvis were performed. For evaluation of distant metastases, patients underwent wholebody bone scanning and ${ }^{18} \mathrm{~F}$-fluorodeoxyglucose positron emission tomography (FDG-PET).

\section{Treatment}

RT was performed with three-dimensional conformal RT (3D-CRT) or intensity-modulated RT (IMRT) with helical tomotherapy (Tomotherapy Inc., Madison, WI) starting on day 1 of chemotherapy. A conventional fractionation schedule (daily 1.8-2.0 Gy per fraction, 5 days per week) and conedown technique were used in all patients. The gross tumor volume (GTV) was delineated using positron emission tomography and CT fusion on the MIM software (Cleveland,
$\mathrm{OH}$ ) or Pinnacle Radiotherapy Planning System (Phillips Medical System, Andover, MA). The initial clinical target volume (CTV) included the GTV plus a margin of at least 5 $\mathrm{cm}$ longitudinally and $2 \mathrm{~cm}$ radially. The initial CTV received 30.6-50.4 Gy (median dose, $36 \mathrm{~Gy}$ ) with anterior-posterior parallel opposite fields to reduce lung dose. At the time of cone-down, final CTV encompassed the GTV with a $2 \mathrm{~cm}$ margin longitudinally and radially. The total radiation dose ranged from 45.0 to $66.6 \mathrm{~Gy}$, with a median dose of $63 \mathrm{~Gy}$.

Chemotherapy was administered to all patients using a 5-fluorouracil (5-FU)-based regimen, except for five patients (2.1\%) who underwent cisplatin alone because of their medical condition. Overall, 217 patients (91.9\% of all patients) were treated with a 5-FU/cisplatin (FP) regimen, while 14 $(5.9 \%)$ underwent 5-FU monotherapy. During RT, two cycles of FP chemotherapy were administered concurrently. Patients had a 4-week break after completing RT, after which they received additional maintenance chemotherapy if a medical oncologist determined that their performance status and medical condition would allow this. 5-FU was administered at $500-1,250 \mathrm{mg} / \mathrm{m}^{2}$ daily as a continuous infusion using a portable electronic pump on days 1-4, while cisplatin was administered at $40-100 \mathrm{mg} / \mathrm{m}^{2}$ on day 1 and during RT sessions.

\section{Follow-up}

All patients were examined weekly during RT to monitor treatment toxicities and their general condition. After completion of CRT, patients were followed at 3-month intervals for the first 3 years, 6-month intervals for the next 2 years, and annually thereafter. Follow-up sessions included physical examination, barium swallow, chest CT, FDG-PET, EGD, and toxicity evaluation. Treatment-related toxicities were recorded according to the Common Toxicity Criteria for Adverse Events ver. 4.0. Tumor response was assessed pathologically based on endoscopic biopsy, as well as clinically based on follow-up imaging studies within three months of completion of CRT according to the Response Evaluation Criteria for Solid Tumors (RECIST) ver. 1.1. Recurrences were confirmed histologically or using conclusive imaging studies if pathological confirmation was not achieved. If loco-regional recurrences were confirmed, they were classified into central, marginal, or outfield based on the location of the recurrent tumor. Marginal recurrences were defined as recurred tumors located inside the initial RT field, but outside of the cone-down RT field. Disease recurrences outside of the esophagus and regional lymph nodes were considered distant metastases. 
Table 1. Patient characteristics

\begin{tabular}{|c|c|c|c|}
\hline Characteristic & $\begin{array}{l}\text { Standard dose } \\
\qquad(\mathrm{n}=120)\end{array}$ & $\begin{array}{l}\text { High dose } \\
\qquad(\mathrm{n}=116)\end{array}$ & p-value \\
\hline Age, mean (range, yr) & $66.0(41-81)$ & $67.0(30-86)$ & 0.924 \\
\hline \multicolumn{4}{|l|}{ Sex } \\
\hline Male & $114(95.0)$ & $112(96.6)$ & 0.749 \\
\hline Female & $6(5.0)$ & $4(3.4)$ & \\
\hline \multicolumn{4}{|l|}{ Karnofsky performance status } \\
\hline $90-100$ & $97(80.8)$ & $77(67.2)$ & 0.017 \\
\hline $60-80$ & $23(19.2)$ & $38(32.8)$ & \\
\hline \multicolumn{4}{|l|}{ Pathology } \\
\hline Squamous cell carcinoma & $117(97.5)$ & $113(97.4)$ & 0.879 \\
\hline Adenocarcinoma & $3(2.5)$ & $3(2.6)$ & \\
\hline \multicolumn{4}{|l|}{ Histologic grade } \\
\hline Well differentiated & $15(12.5)$ & $11(9.5)$ & 0.887 \\
\hline Moderately differentiated & $60(50.0)$ & $58(50.0)$ & \\
\hline Poorly differentiated & $34(28.3)$ & $36(31.0)$ & \\
\hline Unknown & $11(9.2)$ & $11(9.5)$ & \\
\hline \multicolumn{4}{|l|}{ Tumor length (cm) } \\
\hline$\leq 5$ & $66(55.0)$ & $58(50.0)$ & 0.442 \\
\hline$>5$ & $54(45.0)$ & $58(50.0)$ & \\
\hline \multicolumn{4}{|l|}{ Tumor location } \\
\hline Cervical & $5(4.2)$ & $11(9.5)$ & 0.038 \\
\hline Upper thoracic & $27(22.5)$ & $31(26.7)$ & \\
\hline Mid thoracic & $55(45.8)$ & $58(50.0)$ & \\
\hline Lower thoracic & $33(27.5)$ & $16(13.8)$ & \\
\hline \multicolumn{4}{|l|}{ Clinical T stage } \\
\hline cT1 & $10(8.4)$ & $8(6.9)$ & 0.828 \\
\hline cT2 & $27(22.5)$ & $23(19.8)$ & \\
\hline cT3 & $64(53.3)$ & $62(53.5)$ & \\
\hline cT4 & $19(15.8)$ & $23(19.8)$ & \\
\hline \multicolumn{4}{|l|}{ Clinical N stage } \\
\hline cN0 & $19(15.8)$ & $12(10.3)$ & 0.555 \\
\hline cN1 & $86(71.7)$ & $90(77.6)$ & \\
\hline $\mathrm{cN} 2$ & $14(11.7)$ & $12(10.3)$ & \\
\hline cN3 & $1(0.8)$ & $2(1.8)$ & \\
\hline \multicolumn{4}{|l|}{ Stage } \\
\hline II & $46(38.3)$ & $32(27.6)$ & 0.079 \\
\hline III & $74(61.7)$ & $84(72.4)$ & \\
\hline
\end{tabular}

Values are presented as number $(\%)$.

\section{Statistical analysis}

Patients were grouped by total radiation dose, with the high-dose group receiving $\geq 60 \mathrm{~Gy}$ and the standard dose group $<60$ Gy. Study endpoints were LRC and survival. Survival duration was calculated from the date of diagnosis to the corresponding event (loco-regional recurrence, distant metastasis [DM], or death). Continuous variables between the two groups were compared using independent $t$ tests based on baseline characteristics. The Pearson's chi-square test or Fisher exact test were used as appropriate to compare categorical variables. The Kaplan-Meier method with logrank test was used to analyze survival outcomes between groups. Multivariate analysis using the stepwise Cox proportional hazards regression model was performed to identify prognostic factors for LRC and OS (inclusion criteria, $p<0.10)$. All statistical tests were two-sided with significance defined as $p<0.05$. Data were analyzed using the IBM SPSS software ver. 20.0 (IBM Corp., Armonk, NY). 


\section{Results}

Of the 236 patients analyzed in our study, 120 received $<60$ Gy of RT (standard-dose group) and 116 patients received $\geq 60$ Gy (high-dose group). Patient characteristics are shown in Table 1 . No statistically significant differences were observed between groups with respect to age, sex, histologic subtype, tumor length, clinical T stage, N stage, or clinical stage distribution. Most patients were male $(96 \%)$ and had squamous cell carcinoma $(97.5 \%)$. More patients with stage III disease were included in the high-dose group, although the difference was not significant $(72.4 \%$ vs. $61.7 \%$, $\mathrm{p}=0.079$ ). Karnofsky performance status and tumor location were the only factors that showed statistically significant differences between the two groups, and there were more patients with better performance statuses and lower thoracic esophageal tumors in the standard-dose group. Initial FDGPET was performed in $71.2 \%$ of all patients, with no significant difference between groups $(76.7 \%$ in the standard-dose group vs. $65.5 \%$ in the high-dose group).

\section{Details regarding treatment and follow-up}

Patient treatment details are summarized in Table 2. Most patients received FP-based chemotherapy, and the proportion of patients treated with FP was similar between groups $(p=0.742)$. The median doses of $5-F U$ and cisplatin were also similar in both groups. Maintenance chemotherapy following CRT was administered to 147 patients (62.3\%), including 66 in the standard-dose group and 81 in the high-dose group (55\% vs. $69.8 \%$ respectively, $\mathrm{p}=0.019$ ). With the exception of four patients who underwent IMRT with tomotherapy, RT was performed with 3D-CRT. The median radiation dose was 50.4 Gy (range, 45 to $59.4 \mathrm{~Gy}$ ) in the standard-dose group and $63 \mathrm{~Gy}$ (range, 60 to $66.6 \mathrm{~Gy}$ ) in the high-dose group. The median follow-up period was 19.4 months (range, 2.2 to 164.7 months) for all patients and 50.8 months (range, 4.9 to 164.7 months) for those who survived.

\section{Survival outcomes and tumor response}

The median OS and progression-free survival (PFS) times for all patients were 26.2 months and 13.2 months, respectively. Comparisons of LRC, distant metastasis-free survival (DMFS), PFS, and OS between the two dose groups are shown in Fig. 1. All endpoints except DMFS were found to have statistically significant differences favoring the highdose group. The 2-year and 5-year LRC rates of all patients were $60.0 \%$ and $48.4 \%$, respectively. The 5 -year LRC rates were significantly different between groups $(59.7 \%$ in the high-dose group and $37.3 \%$ in the standard-dose group, $\mathrm{p}=0.002$ ) (Fig. 1A). Although DMFS rates were not significantly different according to the RT dose, PFS rates were sig-

Table 2. Treatment characteristics

\begin{tabular}{|c|c|c|c|}
\hline Characteristic & $\begin{array}{l}\text { Standard dose } \\
\quad(n=120)\end{array}$ & $\begin{array}{l}\text { High dose } \\
(n=116)\end{array}$ & p-value \\
\hline \multicolumn{4}{|l|}{ RT modality } \\
\hline 3D-CRT & $119(99.2)$ & $113(97.4)$ & 0.363 \\
\hline IMRT & $1(0.8)$ & $3(2.6)$ & \\
\hline \multicolumn{4}{|l|}{ RT dose, median (range, Gy) } \\
\hline Total & $50.4(45.0-59.4)$ & $63.0(60.0-66.6)$ & $<0.001$ \\
\hline Fractional & $1.8(1.8-2.5)$ & $1.8(1.8-2.0)$ & \\
\hline \multicolumn{4}{|l|}{ Chemotherapy regimen } \\
\hline 5-Fluorouracil+cisplatin & $111(92.5)$ & $106(91.4)$ & $0.742^{\mathrm{a})}$ \\
\hline 5-Fluorouracil monotherapy & $6(5.0)$ & $8(6.9)$ & \\
\hline Others & $3(2.5)$ & $2(1.7)$ & \\
\hline \multicolumn{4}{|l|}{ Median dose of chemotherapy } \\
\hline 5-Fluorouracil $\left(\mathrm{mg} / \mathrm{m}^{2}\right)$ & $1,000(500-1,250)$ & $1,000(500-1,250)$ & 0.942 \\
\hline Cisplatin $\left(\mathrm{mg} / \mathrm{m}^{2}\right)$ & $80(40-100)$ & $80(50-100)$ & 0.470 \\
\hline \multicolumn{4}{|l|}{ Maintenance chemotherapy } \\
\hline Yes & $66(55.0)$ & $81(69.8)$ & 0.019 \\
\hline No & $54(45.0)$ & $35(30.2)$ & \\
\hline
\end{tabular}

Values are presented as number (\%). 3D-CRT, 3 dimensional-conformal radiotherapy; IMRT, intensity-modulated radiotherapy; RT, radiotherapy. ${ }^{\text {a) }}$ Fisher exact test. 
A

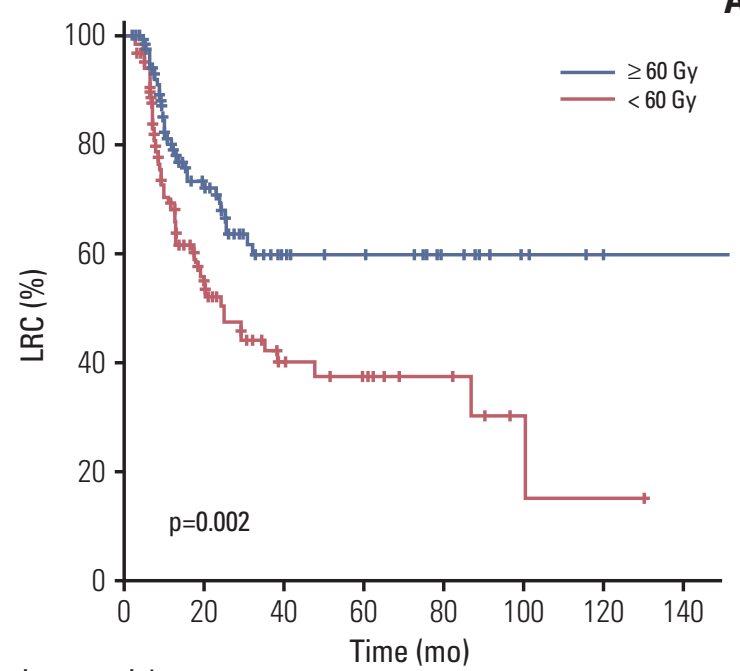

Patients at risk

$\begin{array}{lllllrlll}\geq 60 \mathrm{~Gy} & 116 & 55 & 22 & 17 & 10 & 5 & 2 & 1 \\ <60 \mathrm{~Gy} & 120 & 40 & 17 & 10 & 6 & 2 & 1 & 0\end{array}$

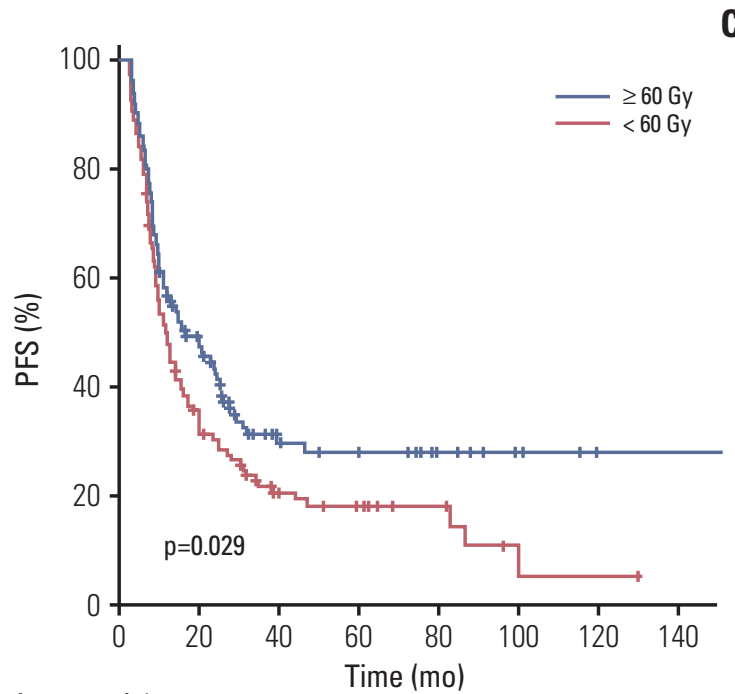

Patients at risk

$\begin{array}{lllllllll}\geq 60 \mathrm{~Gy} & 116 & 49 & 19 & 16 & 9 & 5 & 2 & 1 \\ <60 \mathrm{~Gy} & 120 & 39 & 18 & 10 & 6 & 2 & 1 & 0\end{array}$

C

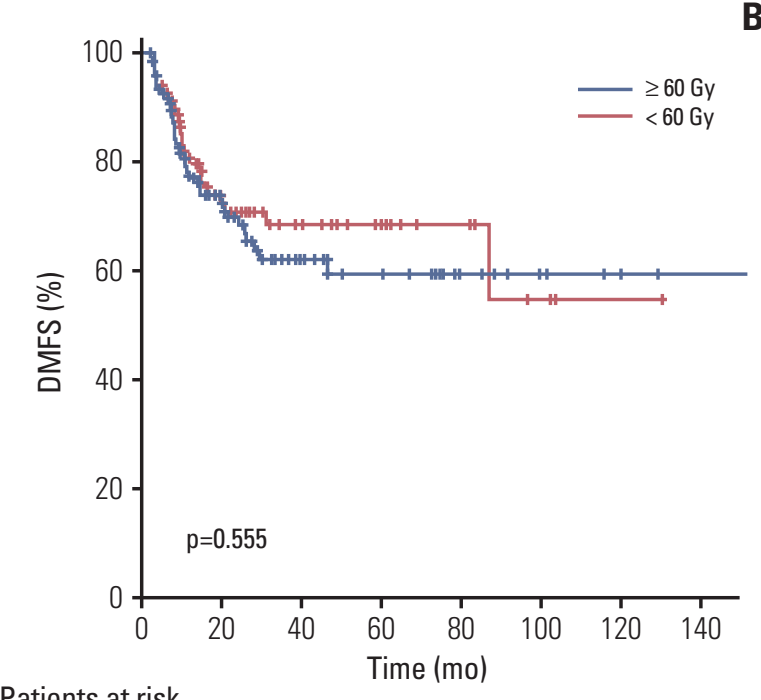

Patients at risk

$\begin{array}{lllllllll}\geq 60 \mathrm{~Gy} & 116 & 54 & 27 & 20 & 10 & 6 & 3 & 2\end{array}$

$\begin{array}{lllllllll}<60 \mathrm{~Gy} & 120 & 46 & 22 & 12 & 8 & 3 & 1 & 0\end{array}$

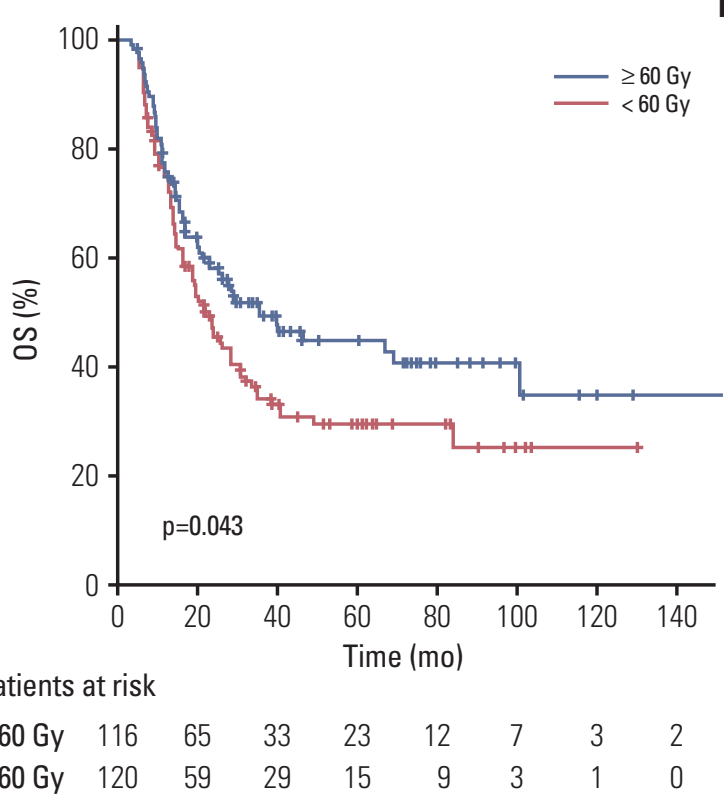

Fig. 1. Kaplan-Meier curves of locoregional control (LRC) (A), distant metastasis-free survival (DMFS) (B), progression-free survival (PFS) (C), and overall survival (OS) (D).

nificantly different between the two dosing groups (median PFS, 11.7 months vs. 16.7 months in the standard-dose and high-dose groups, respectively; $\mathrm{p}=0.029$ ) (Fig. 1B and C). Furthermore, OS rates were significantly different between patients treated with $<60$ Gy and $\geq 60 \mathrm{~Gy}$ (median, 22.3 months vs. 35.1 months, respectively; $\mathrm{p}=0.043$ ) (Fig. 1D). Radiation doses were grouped into intervals of $5 \mathrm{~Gy}$ and plotted against LRC durations to investigate whether a doseresponse relationship exists between RT dose and LRC (Fig. 2). A positive correlation was observed between RT 


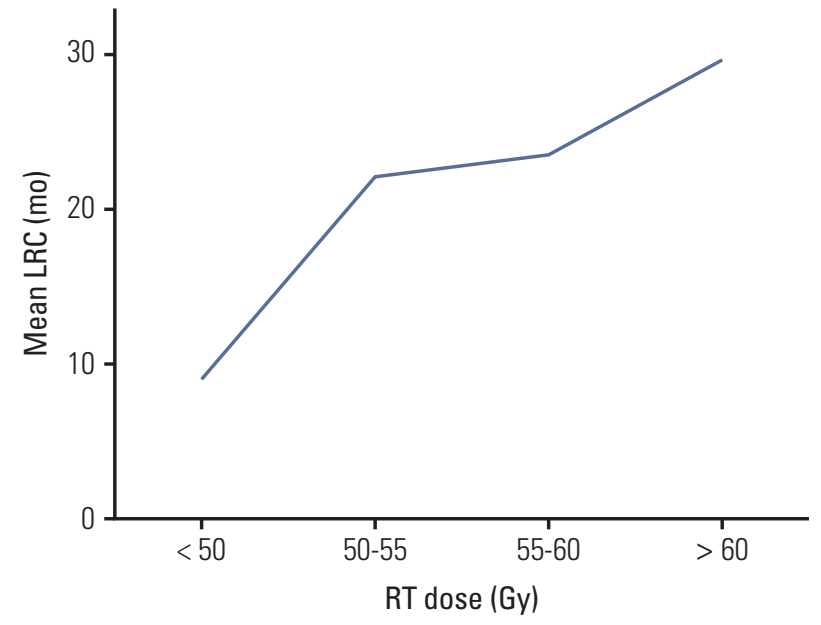

Fig. 2. Dose response relationship between radiotherapy (RT) dose and loco-regional control (LRC) durations.

dose and LRC rate in the setting of definitive CRT.

The total treatment response rate was $94 \%$ for all patients. Complete response (CR) was achieved in 125 patients (53\%), including 53 in the standard-dose group and 72 in the highdose group. CR rates were significantly higher in the highdose group than in the standard-dose group (62.1\% vs. $44.2 \%$, respectively; $\mathrm{p}=0.006$ ). The partial response rates were $47.5 \%$ in the standard-dose group and $34.5 \%$ in the high-dose group. The rates of stable disease (SD) and progressive disease (PD) were $5.0 \%$ and $3.3 \%$ in the standard-dose group, while they were $2.6 \%$ and $0.9 \%$ in the high-dose group, respectively, with no significant differences $(\mathrm{SD}, \mathrm{p}=0.500$; $\mathrm{PD}$, $\mathrm{p}=0.186$ ). The failure patterns are summarized in Table 3 . A total of 141 patients $(59.7 \%)$ experienced treatment failures, including loco-regional failure (LRF) alone in 77 patients
(32.6\%), DM alone in 50 (21.2\%), and both LRF and DM in 14 (5.9\%). The number of patients with LRF alone differed significantly between two groups (39.2\% vs. $25.9 \%$ in the standard-dose vs. high-dose groups, respectively; $\mathrm{p}=0.029$ ). The rate of central failures was two-fold higher in the standarddose group (26.7\% vs. $12.1 \%$, $\mathrm{p}=0.005)$, and DM occurred more frequently in the high-dose group $(25.9 \%$ vs. $16.7 \%$, $\mathrm{p}=0.023$ ).

\section{Prognostic factors and treatment-related toxicities}

The results of univariate and multivariate analyses are shown in Table 4. Univariate analysis revealed that RT dose and the use of maintenance chemotherapy were significant prognostic factors associated with LRC. Multivariate analysis showed that RT dose $\geq 60$ Gy and the use of maintenance chemotherapy remained independent predictors of improved LRC. For OS, Karnofsky performance status, clinical T stage, American Joint Committee on Cancer (AJCC) stage, RT dose, pretreatment stricture, and the use of maintenance chemotherapy were found to be significant risk factors upon univariate analysis. Finally, multivariate analysis identified clinical stage, RT dose $\geq 60 \mathrm{~Gy}$, and use of maintenance chemotherapy as independent prognostic factors correlated with OS.

Treatment-related toxicities of grade $\geq 2$ occurred in 38 patients, with 19 in each of the standard-dose and high-dose groups. No significant differences was found between groups ( $\mathrm{p}=0.929$ ). Toxicities of grades $\geq 3$ occurred in 21 patients, with six patients in each group having grade 3 esophageal stenosis, one in the high-dose group having grade 3 mediastinitis and two in the standard-dose group having grade 3 radiation-induced pneumonitis. Moreover, one patient in each group had a grade 3 fistula, while one in the high-dose group had a grade 4 fistula. Three patients had treatment-related grade 5 toxicities, with two in the standard-

Table 3. Pattern of failures

\begin{tabular}{|c|c|c|c|}
\hline Primary tumor response & $\begin{array}{l}\text { Standard-dose group } \\
\qquad(<60 \mathrm{~Gy})\end{array}$ & $\begin{array}{l}\text { High-dose group } \\
\qquad(\geq 60 \mathrm{~Gy})\end{array}$ & p-value \\
\hline LRF only & $47(39.2)$ & $30(25.9)$ & 0.029 \\
\hline Central failure & $32(26.7)$ & $14(12.1)$ & 0.005 \\
\hline Marginal failure & $4(3.3)$ & $6(5.2)$ & $0.534^{\mathrm{a})}$ \\
\hline Out-field failure & $11(9.2)$ & $10(8.6)$ & 0.883 \\
\hline DM only & $20(16.7)$ & $30(25.9)$ & 0.023 \\
\hline Both LRF and DM & $8(6.7)$ & $6(5.2)$ & 0.627 \\
\hline Total & $75 / 120(62.5)$ & $66 / 116(57.0)$ & \\
\hline
\end{tabular}

Values are presented as number (\%). LRF, loco-regional failure; DM, distant metastasis. ${ }^{a}$ Fisher exact test. 


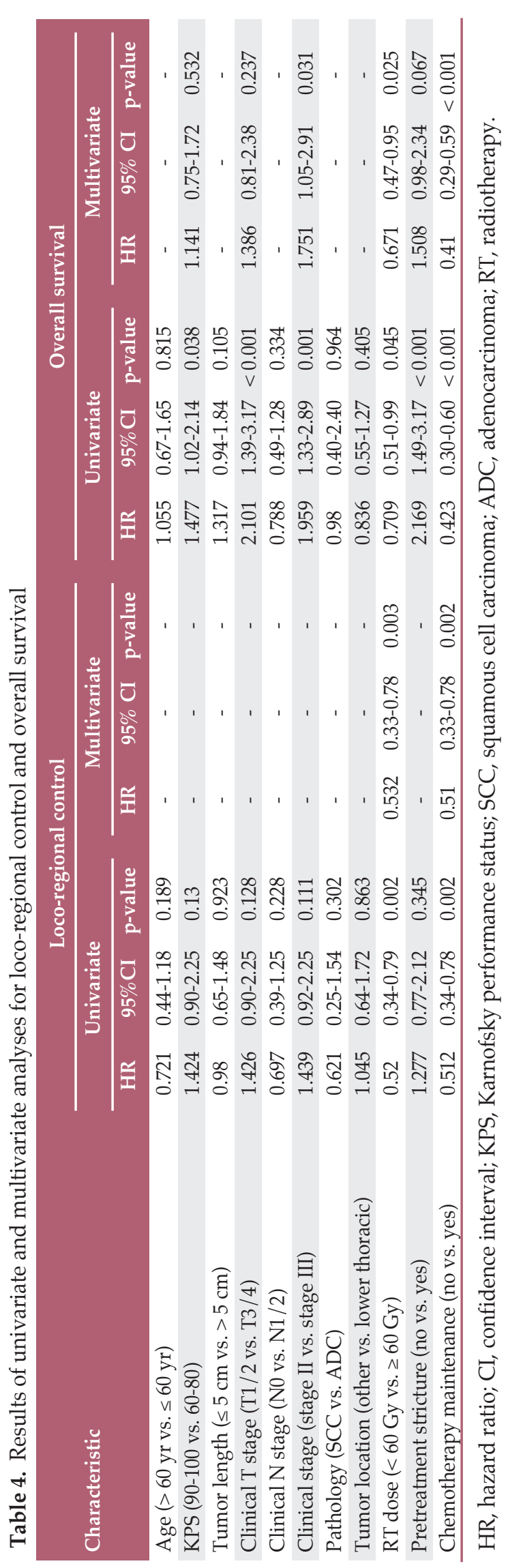

dose group dying from an esophageal fistula and esophageal perforation, respectively, and one in the high-dose dying from massive esophageal hemorrhage. These patients were all receiving maintenance chemotherapy after the end of CRT when they died, having EGD-confirmed residual tumors.

\section{Discussion}

In this study, we investigated the correlation between radiation dose and LRC in patients with stage II-III esophageal cancer treated with definitive CRT. The results of the current study suggest that patients who received a total dose $\geq 60$ Gy of RT had significantly better LRC, PFS, and OS than patients receiving $<60 \mathrm{~Gy}$ when treated with concurrent chemotherapy. Furthermore, our data suggest the existence of a positive correlation between radiation dose and $L R C$ rate.

Based on the results of the RTOG 85-01 trial [5], definitive CRT was established as the standard treatment option for localized esophageal cancer selected for nonsurgical treatment. In this trial, the 5 -year OS rate was $26 \%$ for patients in the combined-modality group and $0 \%$ for those in the RTalone group $(\mathrm{p}<0.001)$. Persistent tumors were also less common in the combined modality group ( $26 \%$ vs. $37 \%)$, as were distant metastases as the first site of treatment failure $(16 \%$ vs. 30\%). The radiation dose of 50 Gy used for the combinedmodality arm in the RTOG 85-01 trial became a preferred dose of RT in definitive CRT settings.

However, this dose requires further investigation because 50 Gy of radiation with conventional fractionations is generally considered inadequate to control gross tumors $[11,12]$. In the RTOG 94-05 phase III trial, the optimal radiation dose was further investigated $[8,9]$. A total of 236 patients with locally advanced esophageal cancer were randomly selected to receive a combined therapy consisting of FP chemotherapy concurrently with high-dose (64.8 Gy) versus standarddose (50.4 Gy) RT. There were no significant differences in median survival (13.0 months vs. 18.1 months), 2-year survival ( $31 \%$ vs. $40 \%)$, or LRF and loco-regional persistence of disease (56\% vs. $52 \%$ ) between the high-dose and standarddose groups, respectively. Although 11 treatment-related deaths occurred in the high-dose group, while there were only two in the standard-dose arm, seven of the 11 deaths occurred before the radiation dose reached 50.4 Gy. Moreover, the radiation technique used in that study was twodimensional, and the margins applied to the target volume were larger than those used in current practice, which may have increased the probability of toxicities. Furthermore, a significantly lower dose of 5-FU was administered to patients 
in the high-dose arm, which could have negatively affected the outcomes of the high-dose arm. Because of such drawbacks, the benefit of high-dose RT with modern techniques remains controversial.

Several studies have attempted to verify the benefit of radiation dose escalation in definitive CRT for locally advanced esophageal cancer [13-15]. Zhang et al. [14] investigated 69 patients with stage II-III unresectable esophageal cancer treated with CRT, including 43 who received $\leq 51$ Gy and 26 who received $>51 \mathrm{~Gy}$. They found that patients in the higher dose group had better 3-year local control (36\% vs. $19 \%)$ and disease-free survival (25\% vs. $10 \%)$ than those in the low-dose group, but that OS was not significantly different ( $13 \%$ vs. $3 \%, \mathrm{p}=0.054)$. The complete clinical response rate was also significantly greater in the high-dose group (46\% vs. $23 \%, \mathrm{p}=0.048$ ). However, their study was limited owing to its small number of patients, retrospective setting, and varying fractionation schedules in the standard-dose arm (30 Gy in 10 fractions). The results of a phase II study also revealed that selective radiation dose escalation in definitive CRT settings yields promising results without surgery or adjuvant chemotherapy [13]. The preliminary results from our previous report [16] suggested a benefit for high-dose RT in stage II-III esophageal cancer patients. The effects of RT $\geq 60$ Gy with concurrent chemotherapy were evaluated in 126 patients. The high-dose group showed significantly improved LRC (2-year LRC rate, $69 \%$ vs. $32 \%$; $<<0.01$ ) and PFS (2-year PFS, $47 \%$ vs. 20\%; $\mathrm{p}=0.01$ ) relative to the standard-dose group. However, there was no significant difference in OS between groups (median, 28 months vs. 18 months respectively; $\mathrm{p}=0.26$ ).

In this study, we included a relatively large number of patients, all of whom received RT with conventional fractionations (1.8-2.0 Gy per fraction) and modern techniques (3DCRT or IMRT). For all patients, the median OS and PFS rates were 26.2 and 13.2 months, respectively, which were more favorable than the results of other studies [17]. In the RTOG 94-05 trial [8], the median survival was 18.1 months in the standard-dose arm and 13.0 months in the high-dose arm. In the FFCD 9102 trial $[18,19]$, which compared CRT alone to CRT followed by surgery in patients with locally advanced tumors, the median OS was 19.3 months in the CRT arm. In a study conducted by Hurmuzlu et al. [20], 46 patients were treated with high-dose RT (66 Gy in 33 fractions) concurrently with FP chemotherapy. The median OS and diseasespecific survival were only 10.8 months and 11 months, respectively.

Radiation dose to the heart was recently reported to have adverse effects on survival, with mean heart dose noted in patients with breast cancer and with V5 and V30 noted in lung cancer patients in the RTOG 0617 trial $[21,22]$. Although a study conducted to determine the independent impact of heart dose on early OS revealed that heart dose was not associated with early survival outcomes when lung dose was taken into account [23], heart dose should not be overlooked during RT planning. Heart dose is also a concern during treatment planning for esophageal cancer because of the close proximity between the two organs. Therefore, we performed survival analysis according to the tumor location by dividing patients into those with lower thoracic tumors and those with tumors in other locations. High-dose radiation $\geq 60$ Gy showed no significant OS benefit in patients with lower thoracic lesions (hazard ratio [HR], 0.681; 95\% confidence interval [CI], 0.288 to $1.612 ; \mathrm{p}=0.382$ ). Conversely, $\mathrm{OS}$ was significantly better in patients with tumors in other locations (HR, $0.678 ; 95 \% \mathrm{CI}, 0.467$ to $0.985 ; \mathrm{p}=0.041$ ). These results indicate a possible detrimental effect of cardiac dose on early survival in esophageal cancer patients. Accordingly, follow-up studies are warranted to assess the effects of cardiac dose on heart disease or mortality.

It should be noted that this study had several limitations. Specifically, this study has limitations stemming from its retrospective nature. Moreover, the chemotherapy regimens used for the patients and the use of maintenance chemotherapy were not uniform, which may have influenced tumor response. Furthermore, patient characteristics were not matched between the two groups, and patients with good performance statuses and lower thoracic lesions were significantly more prevalent in the standard-dose group than in the high-dose group. Better clinical outcomes in the highdose group despite a lower performance status suggest that the benefit of high-dose RT outweighs this disadvantage. Finally, it is possible that treatment-related toxicities were underestimated due to the study's retrospective setting.

\section{Conclusion}

Higher radiation dose ( $\geq 60 \mathrm{~Gy}$ ) was found to be associated with increased LRC, PFS, and OS in patients with stage II-III esophageal cancer treated with definitive CRT. These results suggest that radiation dose escalation may improve survival outcomes for such patients. A prospective trial evaluating the optimal dose of radiation is warranted in the future.

\section{Conflicts of Interest}

Conflict of interest relevant to this article was not reported. 


\section{References}

1. Global Burden of Disease Cancer Collaboration, Fitzmaurice C, Dicker D, Pain A, Hamavid H, Moradi-Lakeh M, et al. The global burden of cancer 2013. JAMA Oncol. 2015;1:505-27.

2. Enzinger PC, Mayer RJ. Esophageal cancer. N Engl J Med. 2003;349:2241-52.

3. Bosset JF, Gignoux M, Triboulet JP, Tiret E, Mantion G, Elias $\mathrm{D}$, et al. Chemoradiotherapy followed by surgery compared with surgery alone in squamous-cell cancer of the esophagus. N Engl J Med. 1997;337:161-7.

4. Tepper J, Krasna MJ, Niedzwiecki D, Hollis D, Reed CE, Goldberg R, et al. Phase III trial of trimodality therapy with cisplatin, fluorouracil, radiotherapy, and surgery compared with surgery alone for esophageal cancer: CALGB 9781. J Clin Oncol. 2008;26:1086-92.

5. Cooper JS, Guo MD, Herskovic A, Macdonald JS, Martenson JA Jr, Al-Sarraf M, et al. Chemoradiotherapy of locally advanced esophageal cancer: long-term follow-up of a prospective randomized trial (RTOG 85-01). Radiation Therapy Oncology Group. JAMA. 1999;281:1623-7.

6. al-Sarraf M, Martz K, Herskovic A, Leichman L, Brindle JS, Vaitkevicius VK, et al. Progress report of combined chemoradiotherapy versus radiotherapy alone in patients with esophageal cancer: an intergroup study. J Clin Oncol. 1997;15: 277-84.

7. Herskovic A, Martz K, al-Sarraf M, Leichman L, Brindle J, Vaitkevicius $\mathrm{V}$, et al. Combined chemotherapy and radiotherapy compared with radiotherapy alone in patients with cancer of the esophagus. N Engl J Med. 1992;326:1593-8.

8. Minsky BD, Pajak TF, Ginsberg RJ, Pisansky TM, Martenson J, Komaki R, et al. INT 0123 (Radiation Therapy Oncology Group 94-05) phase III trial of combined-modality therapy for esophageal cancer: high-dose versus standard-dose radiation therapy. J Clin Oncol. 2002;20:1167-74.

9. Kachnic LA, Winter K, Wasserman T, Kelsen D, Ginsberg R, Pisansky TM, et al. Longitudinal quality-of-life analysis of RTOG 94-05 (Int 0123): a phase III trial of definitive chemoradiotherapy for esophageal cancer. Gastrointest Cancer Res. 2011;4:45-52.

10. National Comprehensive Cancer Network. NCCN guideline [Internet]. Fort Washington, PA: National Comprehensive Cancer Network; 2016 [cited 2016 Jan 4]. Available from: http:// www.nccn.org/professionals/physician_gls/pdf/esop hageal.pdf.

11. Fletcher GH. Keynote address: the scientific basis of the present and future practice of clinical radiotherapy. Int J Radiat Oncol Biol Phys. 1983;9:1073-82.

12. Halperin EC, Wazer DE, Perez CA, Brady LW. Perez and Brady's principles and practice of radiation oncology. 6th ed. Philadelphia, PA: Lippincott Williams \& Wilkins; 2013.

13. Seung SK, Smith JW, Molendyk J, Bader SB, Phillips M, Regan $\mathrm{J}$, et al. Selective dose escalation of chemoradiotherapy for esophageal cancer: role of treatment intensification. Semin Oncol. 2004;31(6 Suppl 18):13-9.

14. Zhang Z, Liao Z, Jin J, Ajani J, Chang JY, Jeter M, et al. Doseresponse relationship in locoregional control for patients with stage II-III esophageal cancer treated with concurrent chemotherapy and radiotherapy. Int J Radiat Oncol Biol Phys. 2005;61:656-64.

15. Song T, Liang X, Fang M, Wu S. High-dose versus conventional-dose irradiation in cisplatin-based definitive concurrent chemoradiotherapy for esophageal cancer: a systematic review and pooled analysis. Expert Rev Anticancer Ther. 2015;15: 1157-69.

16. Suh YG, Lee IJ, Koom WS, Cha J, Lee JY, Kim SK, et al. Highdose versus standard-dose radiotherapy with concurrent chemotherapy in stages II-III esophageal cancer. Jpn J Clin Oncol. 2014;44:534-40.

17. Sasamoto R, Sakai K, Inakoshi H, Sueyama H, Saito M, Sugita $\mathrm{T}$, et al. Long-term results of chemoradiotherapy for locally advanced esophageal cancer, using daily low-dose 5-fluorouracil and cis-diammine-dichloro-platinum (CDDP). Int J Clin Oncol. 2007;12:25-30.

18. Bedenne L, Michel P, Bouche O, Milan C, Mariette C, Conroy $\mathrm{T}$, et al. Chemoradiation followed by surgery compared with chemoradiation alone in squamous cancer of the esophagus: FFCD 9102. J Clin Oncol. 2007;25:1160-8.

19. Vincent J, Mariette C, Pezet D, Huet E, Bonnetain F, Bouche $\mathrm{O}$, et al. Early surgery for failure after chemoradiation in operable thoracic oesophageal cancer: analysis of the non-randomised patients in FFCD 9102 phase III trial: Chemoradiation followed by surgery versus chemoradiation alone. Eur J Cancer. 2015;51:1683-93.

20. Hurmuzlu M, Monge OR, Smaaland R, Viste A. High-dose definitive concomitant chemoradiotherapy in non-metastatic locally advanced esophageal cancer: toxicity and outcome. Dis Esophagus. 2010;23:244-52.

21. Darby SC, McGale P, Taylor CW, Peto R. Long-term mortality from heart disease and lung cancer after radiotherapy for early breast cancer: prospective cohort study of about 300,000 women in US SEER cancer registries. Lancet Oncol. 2005;6: 557-65.

22. Bradley JD, Paulus R, Komaki R, Masters G, Blumenschein G, Schild $S$, et al. Standard-dose versus high-dose conformal radiotherapy with concurrent and consolidation carboplatin plus paclitaxel with or without cetuximab for patients with stage IIIA or IIIB non-small-cell lung cancer (RTOG 0617): a randomised, two-by-two factorial phase 3 study. Lancet Oncol. 2015;16:187-99.

23. Tucker SL, Liu A, Gomez D, Tang LL, Allen P, Yang J, et al. Impact of heart and lung dose on early survival in patients with non-small cell lung cancer treated with chemoradiation. Radiother Oncol. 2016;119:495-500. 